\title{
Behavioral destabilization induced by the selective serotonin reuptake inhibitor fluoxetine
}

Katsunori Kobayashi ${ }^{1,2^{*+}}$, Yumiko Ikeda ${ }^{1 \dagger}$, Hidenori Suzuki ${ }^{1,2}$

\begin{abstract}
Background: Selective serotonin reuptake inhibitors (SSRIs) are widely used to treat mood and anxiety disorders. However, neuronal bases for both beneficial and adverse effects of SSRIs remain poorly understood. We have recently shown that the SSRI fluoxetine can reverse the state of maturation of hippocampal granule cells in adult mice. The granule cell "dematuration" is induced in a large population of granule cells, and greatly changes functional and physiological properties of these cells. Here we show that this unique form of neuronal plasticity is correlated with a distinct change in behavior of mice.
\end{abstract}

Results: We chronically treated adult male mice with fluoxetine, and examined its effect on several forms of behavior of mice. During fluoxetine treatments, mice showed a marked increase in day-to-day fluctuations of home cage activity levels that was characterized by occasional switching between hypoactivity and hyperactivity within a few days. This destabilized cage activity was accompanied by increased anxiety-related behaviors and could be observed up to 4 weeks after withdrawal from fluoxetine. As reported previously, the granule cell dematuration by fluoxetine includes a reduction of synaptic facilitation at the granule cell output, mossy fiber, synapse to the juvenile level. Mossy fiber synaptic facilitation examined electrophysiologically in acute hippocampal slices also remained suppressed after fluoxetine withdrawal and significantly correlated with the fluctuation of cage activity levels in individual mice. Furthermore, in mice lacking the $5-\mathrm{HT}_{4}$ receptor, in which the granule cell dematuration has been shown to be attenuated, fluoxetine had no significant effect on the fluctuation of cage activity levels.

Conclusions: Our results demonstrate that the SSRI fluoxetine can induce marked day-to-day changes in activity levels of mice in the familiar environment, and that the dematuration of the hippocampal granule cells is closely associated with the expression of this destabilized behavior. Based on these results, we propose that the granule cell dematuration can be a potential cellular basis underlying switching-like changes in the behavioral state associated with SSRI treatments.

\section{Background}

Selective serotonin reuptake inhibitors (SSRIs) have been commonly used to treat mood and anxiety disorders, while some severe adverse effects have been reported $[1,2]$. Although SSRIs can immediately change extracellular levels of serotonin in the central nervous system, therapeutic effects of these drugs usually require weeks of treatments [3]. Some of adverse psychiatric effects of SSRIs also emerge with a delayed onset during chronic treatments or even after withdrawal of the

\footnotetext{
* Correspondence: kkatsu-tky@umin.ac.jp

+ Contributed equally

'Department of Pharmacology, Nippon Medical School, 1-1-5 Sendagi,

Bunkyo-ku, Tokyo 113-8602, Japan

Full list of author information is available at the end of the article
}

drugs $[4,5]$. Thus, adaptive or plastic changes in the central nervous system are likely to be involved in adverse effects as well as therapeutic effects of SSRIs. In experimental animals, SSRIs and other antidepressant drugs can generally facilitate adult neurogenesis in the dentate gyrus of the hippocampus, and this process has been suggested to underlie some of behavioral effects of these drugs [6-8]. The facilitatory effect on the adult neurogenesis usually requires a few weeks of administration, which could explain the delayed manifestation of the effects of the drugs at the behavioral level. However, it remains unknown how the facilitated neurogenesis leads to modifications of hippocampal functioning that can cause robust changes in behavior. We have recently shown that chronic treatments with fluoxetine, a widely

\section{() Biomed Central}


used SSRI, can reverse the established state of maturation of the dentate granule cell in adult mice [9]. The change in the state of the granule cell maturation gradually develops over the course of the fluoxetine treatment for a few weeks and is manifested as marked changes in physiological and functional properties of the granule cell that include neuronal excitability, activity-dependent synaptic modifications, and immediate early gene expression [9]. Since this novel form of neuronal plasticity is induced in a large population of the dentate granule cells, it is supposed to have a substantial impact on the operation of hippocampal neuronal circuits and probably on hippocampus-dependent regulation of behaviors. In the present study, we analyzed changes in behaviors of mice treated with fluoxetine in a regimen that is sufficient for the induction of granule cell dematuration, and examined the association between observed behavioral changes and the granule cell dematuration.

\section{Results}

Destabilization of home cage activity by chronic fluoxetine

Fluoxetine was applied for 4 weeks at a dose of 14 or 22 $\mathrm{mg} / \mathrm{kg} /$ day. Our previous study showed that fluoxetine induces dematuration of the dentate granule cells at 22 $\mathrm{mg} / \mathrm{kg} /$ day, but not at $14 \mathrm{mg} / \mathrm{kg} /$ day [9]. In order to assess a behavioral correlate of the granule cell dematuration, we analyzed effects of both doses of fluoxetine on several forms of behaviors of mice. First, activity levels of mice in their home cages were continuously monitored during the treatment (Figure 1A-1F). In some of these mice, electrophysiological recordings were also performed after monitoring cage activity to assess the state of the granule cell maturation (Figure 1A, 1C and $1 \mathrm{E})$. In control mice, the home cage activity levels were quite stable throughout the course of experiments (Figure 1A left) except for a gradual small decline as seen in the averaged data (Figure 1B). After starting administration of fluoxetine at $14 \mathrm{mg} / \mathrm{kg} /$ day (FLX14), the activity level of mice was initially decreased, but remained stable thereafter (Figure $1 \mathrm{C}$ left and $1 \mathrm{D})$. In contrast, fluoxetine at $22 \mathrm{mg} / \mathrm{kg} /$ day (FLX22) caused a distinct change in the home cage activity. Mice treated with FLX22 also exhibited an initial decrease in activity levels (Figure 1E left and $1 F$ ). In about 2 weeks of treatments, however, they started showing a marked day-today fluctuation of activity levels (Figure $1 \mathrm{E}$ left) that was accompanied by occasional switching from hypoactivity to hyperactivity and vice versa in a few days (see also Figure 2A). To quantify this fluctuation of home cage activity, we calculated the coefficient of variation (CV) of activity levels during the last 2 weeks of the treatments. There was a highly significant difference in $\mathrm{CV}$ between FLX22 and other groups (Figure 1G). The mean activity level during the same period tended to be higher in FLX22-treated mice (see Figure 1B, 1D and $1 \mathrm{~F})$, but there was no statistically significant difference between groups $(p>0.05$, rank sum difference $=4.327$ for control vs. FLX22, 12.2 for control vs. FLX14, and 16.53 for FLX14 vs. FLX22).

The granule cell dematuration induced by FLX22 includes reversal of functional maturation of these cells [9]. In the matured state, the synapse between the mossy fiber, the granule cell axon, and CA3 pyramidal cells shows prominent frequency facilitation (see Figure 1A right), and this frequency facilitation is greatly reduced in the immature or dematurated granule cells [9-11]. To directly investigate the relationship between this physiological index of granule cell dematuration and the behavioral change, we made electrophysiological recordings using hippocampal slices prepared from mice whose home cage activity had been monitored. In control and FLX14-treated mice, strong frequency facilitation was induced at the mossy fiber synapse by $1 \mathrm{~Hz}$ stimulation (Figure $1 \mathrm{~A}$ right and $1 \mathrm{C}$ right). In FLX22treated mice that showed marked fluctuation of cage activity levels, frequency facilitation was strongly decreased (Figure 1E right), confirming the induction of the granule cell dematuration in these mice. The magnitude of mossy fiber synaptic facilitation in FLX22-treated mice was negatively correlated with $\mathrm{CV}$ of home cage activity levels in individual mice (Figure $1 \mathrm{H}$ ). Thus, mice with more dematurated mossy fiber synapses exhibited larger changes in fluctuation of activity.

In some cases, we stopped administration of fluoxetine while continuously monitoring the home cage activity (Figure 2A). Although the results were variable, the activity fluctuation could be clearly observed at least up to 4 weeks after discontinuation of the fluoxetine treatment, and one mouse showed marked fluctuation only after the discontinuation (Figure 2A and 2B). Thus, the destabilization of home cage activity by FLX 22 cannot be simply explained by fluctuation of acute actions or tissue concentrations of fluoxetine, but is likely caused by some plastic changes in the central nervous system. We also examined the mossy fiber synaptic transmission in mice withdrawn from FLX22, and found that frequency facilitation remained suppressed 4 weeks after the withdrawal (Figure 2C), suggesting that the granule cells were still in the dematurated state. Taken together, these results indicate that the granule cell dematuration is associated with destabilization of home cage activity of mice.

\section{Increased anxiety-related behaviors caused by chronic fluoxetine}

We further characterized behavioral changes caused by the fluoxetine treatments. FLX14 slightly reduced horizontal 
A

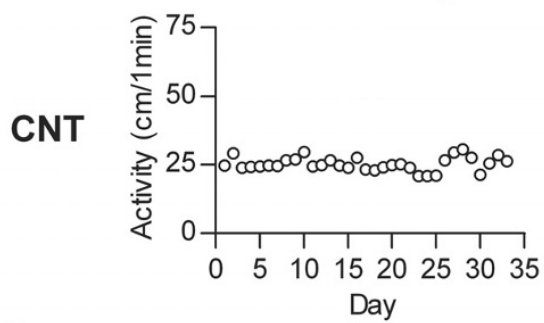

C

FLX14

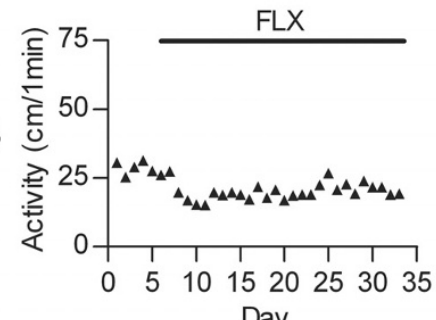

E

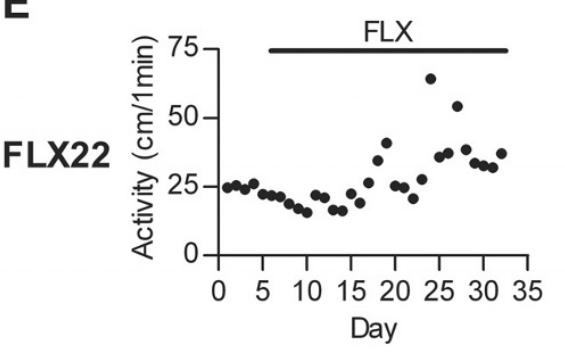

Representative data
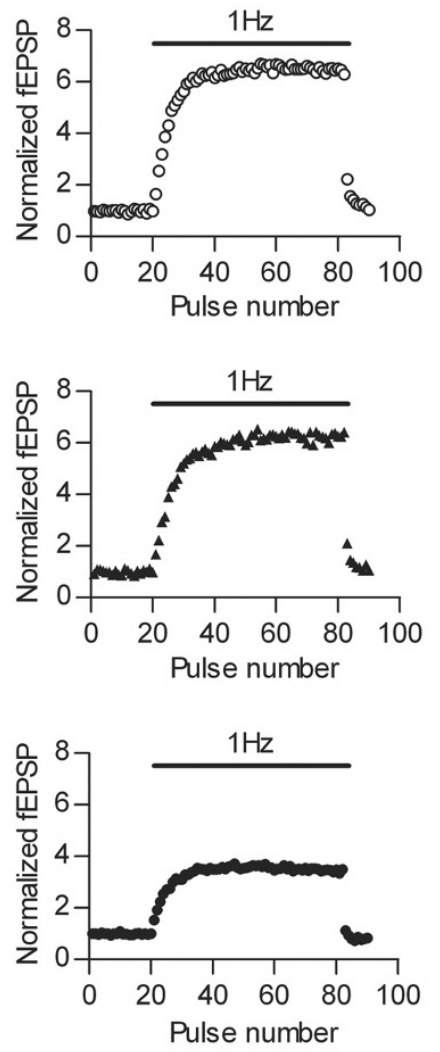

B Summary

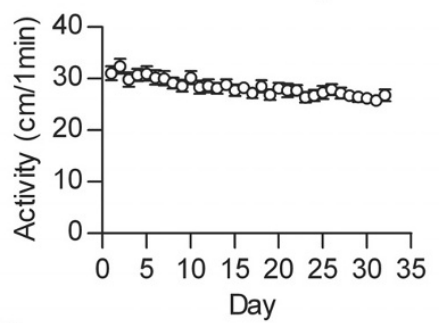

D

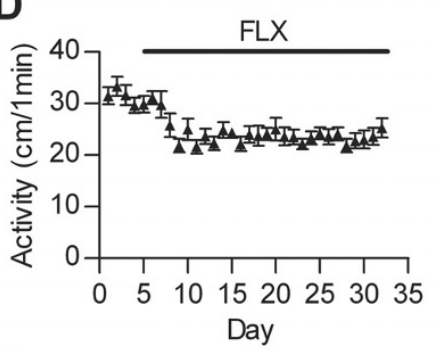

$\mathbf{F}$

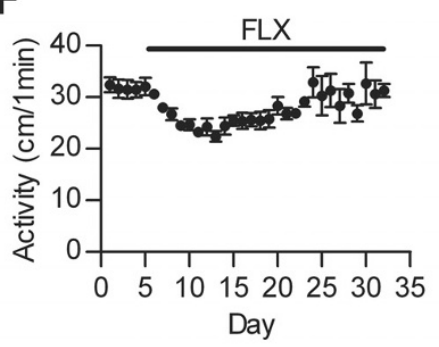

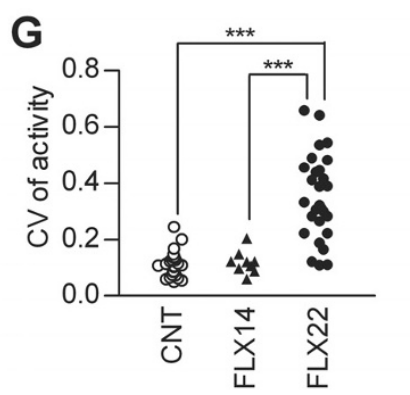

H

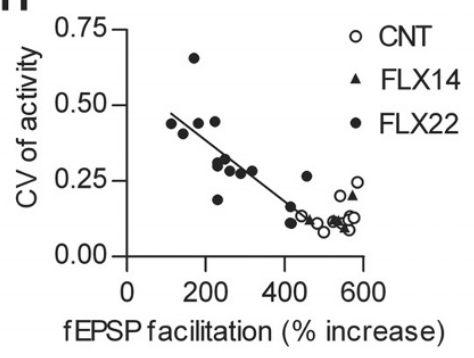

Figure 1 Fluoxetine destabilizes home cage activity. (A) Representative data showing nocturnal locomotor activity levels in home cage (left) and frequency facilitation at the mossy fiber synapse induced by $1 \mathrm{~Hz}$ stimulation (right) in a control (CNT) mouse. (B) Averaged data of nocturnal activity levels in control mice. (C) Representative nocturnal activity and synaptic facilitation, and (D) averaged nocturnal activity in mice treated with $14 \mathrm{mg} / \mathrm{kg} /$ day fluoxetine (FLX14). (E) Representative nocturnal activity and synaptic facilitation, and (F) averaged nocturnal activity in mice treated with $22 \mathrm{mg} / \mathrm{kg} /$ day fluoxetine (FLX22). Representative behavioral and electrophysiological data were obtained from the same mice. Averaged data are presented as mean \pm s.e.m. (G) Coefficient of variation (CV) of activity levels during last 2 weeks of treatments. FLX22 $(n=29)$ mice showed larger variation than control $(n=27$, rank sum difference $=29.48, p<0.0001)$ and FLX14 $(n=9$, rank sum difference $=27.11, p<$ 0.0001). There was no significant difference between control and FLX14 (rank sum difference $=2.37, p>0.05$ ). (H) $\mathrm{CV}$ of activity was negatively correlated with the magnitude of frequency facilitation at the mossy fiber synapse in FLX22 mice $\left(n=16, p=0.0007, r^{2}=0.569\right)$. Each symbol represents a single mouse.

activity of mice in the open-field test (Figure 3A) and light/dark transition test (Figure 3B), but had no significant effects on indexes of anxiety-related behaviors in these tests (Figure $3 \mathrm{~A}$ and $3 \mathrm{~B}$ ) and the elevated plus-maze test (Figure 3C). These results are similar to our previous report of behaviors of mice treated with fluoxetine at
$10 \mathrm{mg} / \mathrm{kg} /$ day [12]. Effects of FLX22 on behaviors in these tests were completely different from those of FLX14. FLX22 had no suppressive effects on the locomotor activity in the open-field test (Figure 4A) and light/dark transition test (Figure 4B), induced hyperactivity in the elevated plus-maze test (Figure 4C), and consistently increased 


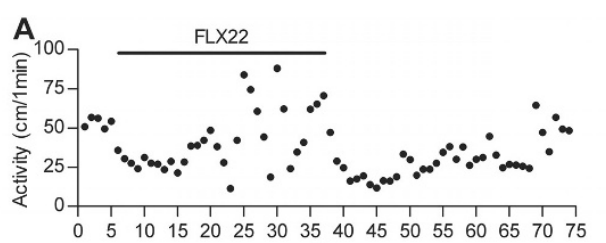

Day
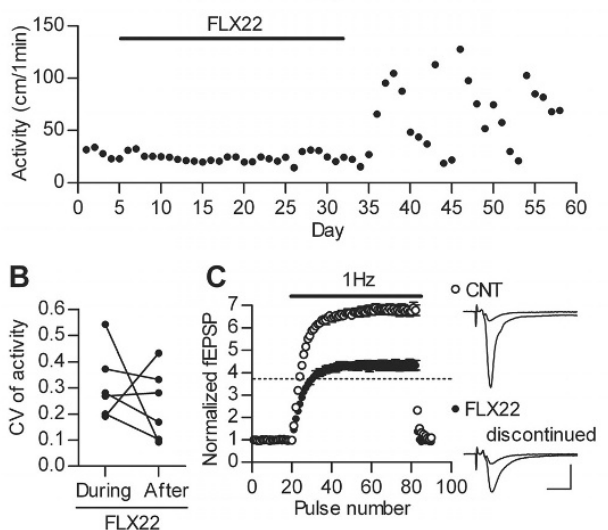

Figure 2 Home cage activity and synaptic transmission after discontinuation of fluoxetine administration. (A) Sample data showing effects of FLX22 administration and withdrawal on nocturnal activity in two different mice. (B) CV of activity during FLX22 treatments and after discontinuation of the treatments. Data points connected by lines were from the same mice. (C) Pooled data showing reduced $1 \mathrm{~Hz}$ frequency facilitation at the mossy fiber synapse 4 weeks after discontinuation of fluoxetine treatments $(n=$ 6 each, $U=0, p=0.0022$ ). The dotted line shows the average level of facilitation in mice treated with FLX22 for 4 to 5 weeks without discontinuation. Sample recordings are averages of 15 consecutive fEPSPs before and during $1 \mathrm{~Hz}$ stimulation. Scale bar: $10 \mathrm{~ms}, 0.5 \mathrm{mV}$. Data are presented as mean \pm s.e.m.

anxiety-related behaviors: FLX22 reduced time spent in the center of the open field (Figure 4A), time spent in the light box (Figure 4B), and relative entry into open arms (Figure 4C). On the other hand, FLX14 and FLX22 had similar effects on depression-related behaviors. Immobile time was increased in the forced swim test, but decreased in the tail suspension test in both conditions (Figure 5A and $5 \mathrm{~B}$ ). Taken together, these results suggest that the granule cell dematuration induced by FLX22 is associated with increased anxiety-related behaviors as well, but not with the depression-related behaviors assessed in the present study.

\section{Requirement of serotonin $5-\mathrm{HT}_{4}$ receptor for behavioral effects of fluoxetine}

We have previously shown that the granule cell dematuration is attenuated in mice lacking the serotonin 5$\mathrm{HT}_{4}$ receptor [9]. To further investigate the association between the granule cell dematuration and behavioral effects of fluoxetine, we carried out the same battery of behavioral tests in $5-\mathrm{HT}_{4}$ receptor-deficient $\left(5-\mathrm{HT}_{4}-/-\right)$
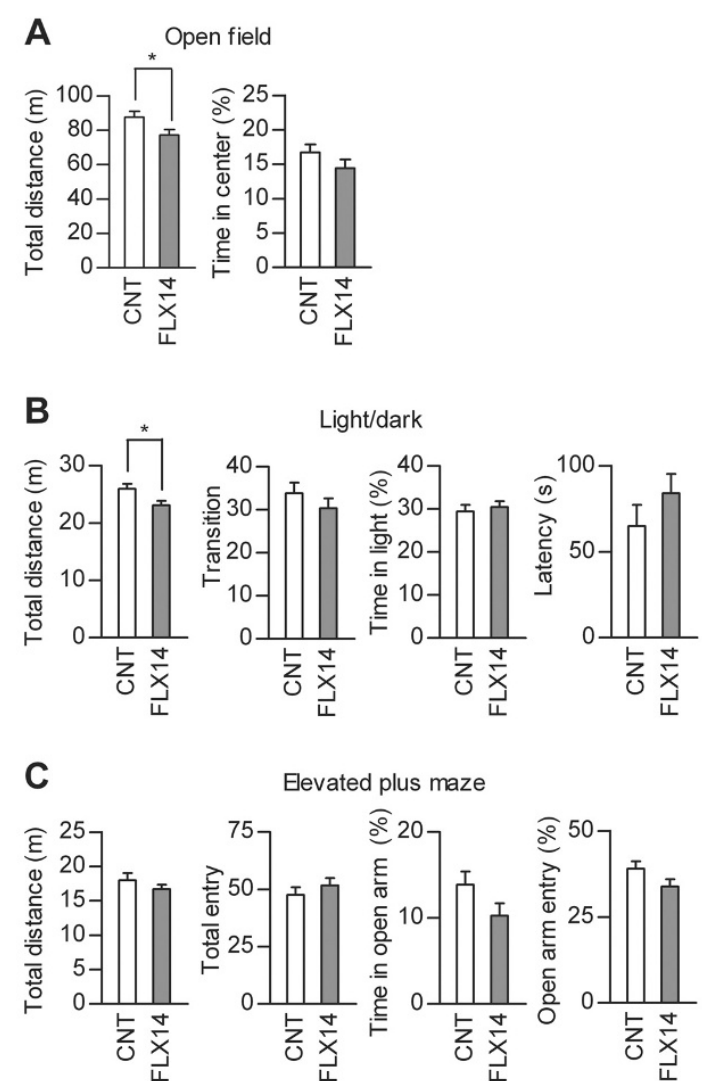

Figure 3 Effects of FLX14 on locomotor activity and anxietyrelated behavior. (A) FLX14 reduced the total distance traveled in the open-field test $(z=2.094, p=0.0363)$, but had no significant effect on time spent in the center of the field $(z=0.952, p=$ 0.3412, CNT: $n=13$, FLX14: $n=12$ ). Time in center is indicated as percent time spent in the center relative to the total time in the field. (B) FLX14 reduced the total distance traveled in the light/dark transition test ( $z=2.203, p=0.0276)$, but had no significant effects on the number of transition between two compartments $(z=0.952$, $p=0.3408)$, time spent in the light box $(z=0.408, p=0.6833)$, or latency to enter the light box ( $z=1.822, p=0.0685, C N T: n=13$, FLX14: $n=12$ ). Time in light is indicated as percent time spent in the light compartment relative to the total test time. (C) In the elevated plus-maze test, FLX14 had no significant effects on the total distance traveled $(z=0.68, p=0.4966)$, the total number of entries into arms $(z=0.897, p=0.3693)$, time spent on open arms $(z=1.523, p=0.1278)$, or entry into open arms $(z=1.768, p=$ 0.0772, CNT: $n=13$, FLX14: $n=12$ ). Time in open arms and open arm entry are indicated as percent time spent on open arms relative to the total test time and the percent number of entries into open arms relative to the total number of entries, respectively. Data are presented as mean \pm s.e.m.

mice with the genetic background of C57BL/6J. As in normal C57BL/6J mice, FLX22 induced destabilization of home cage activity in the wild-type $\left(5-\mathrm{HT}_{4}+/+\right)$ mice (Figure 6A and 6B). In 5- $\mathrm{HT}_{4}-/$ - mice, however, FLX22 reduced mean activity levels in home cages with no significant effect on CV of activity (Figure 6C and 6D). Effects of FLX22 on other forms of behaviors in 5- $\mathrm{HT}_{4}$ 

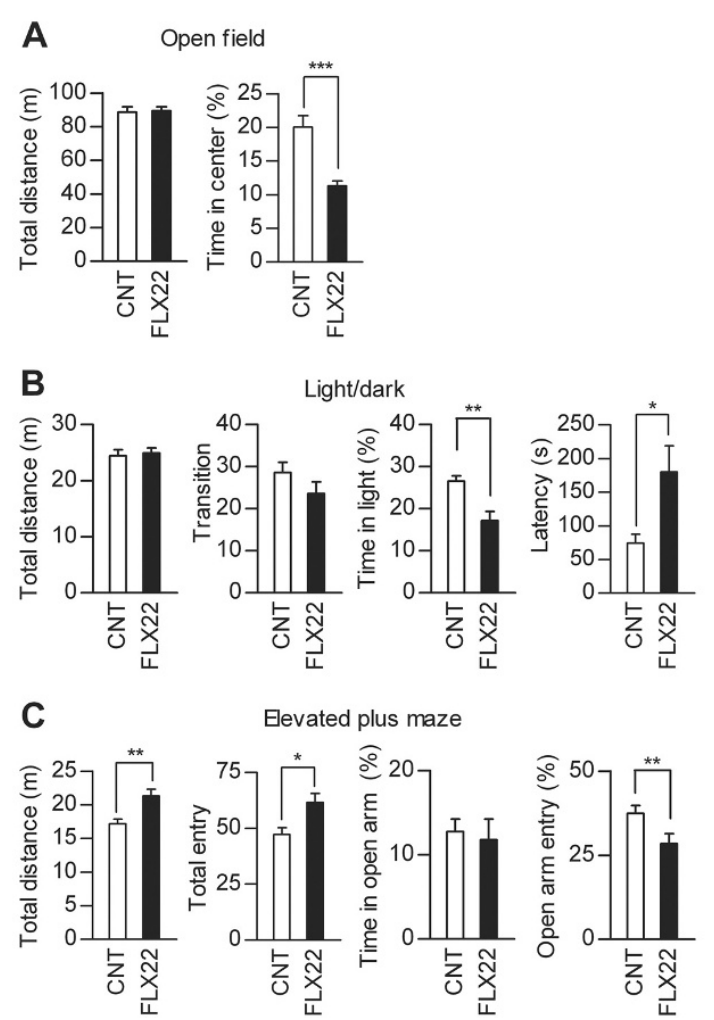

Đevated plus maze
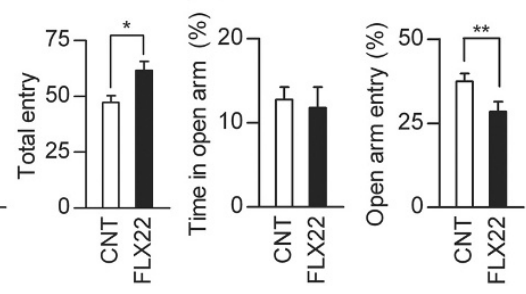

Figure 4 Effects of FLX22 on locomotor activity and anxietyrelated behavior. (A) FLX22 reduced time spent in the center of the open field $(z=4.766, p<0.0001)$, but had no significant effect on the total distance traveled ( $z=0.08, p=0.9361, C N T: n=25$, FLX22: $n=28$ ). (B) FLX22 reduced time spent in the light compartment in the light/dark transition test $(z=3.185, p=0.0015)$ and increased the latency to enter the light compartment $(z=$ $2.217, p=0.0267)$, but had no significant effects on the total distance traveled ( $z=0.176, p=0.8602$ ) or the number of transition between two compartments ( $z=0.983, p=0.3253, \mathrm{CNT}: n=17$, FLX22: $n=21)$. Two fluoxetine-treated mice did not enter the light compartment. (C) FLX22 increased the total distance traveled $(z=$ $2.69, p=0.0072)$ and the number of entries into arms $(z=2.465, p$ $=0.0137)$, and decreased relative entry into open arms ( $z=2.704, p$ $=0.0069)$, but had no significant effect on time in open arms ( $z=$ $1.225, p=0.2205)$ in the elevated plus-maze test (CNT: $n=18$, FLX22: $n=21)$. Percent values are calculated as in Figure 3 .

$+/+$ mice were also generally comparable to those in normal C57BL/6J mice: FLX22 increased anxiety-related behaviors in the open field and light/dark transition tests (Figure 7A and 7B), and increased immobile time in the forced swim test (Figure 7D). However, FLX22 did not significantly change the behaviors of $5-\mathrm{HT}_{4}+/+$ mice in the elevated plus-maze test (Figure 7C) and tail suspension test (Figure 7D), and induced exaggerated anxiety-like responses in the light/dark transition test (Figure 7B). In 5- $\mathrm{HT}_{4} / /$ - mice, FLX22 had no significant effects on behaviors in the open-field, light/dark transition and elevated plus-maze tests (Figure $8 \mathrm{~A}, 8 \mathrm{~B}$ and

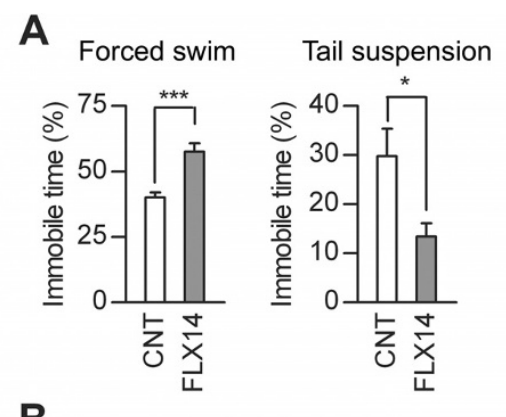

B

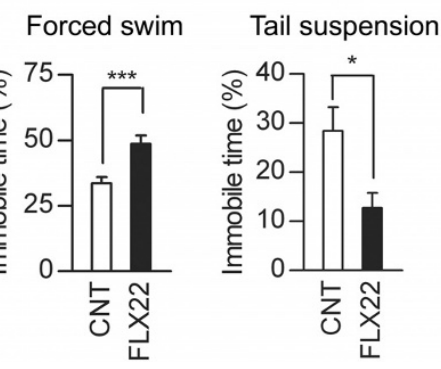

Figure 5 Effects of fluoxetine on depression-related behavior (A) FLX14 increased immobile time in forced swim test (CNT: $n=$ 13, FLX14: $n=12, z=3.726, p=0.0002$ ) and decreased immobile time in tail suspension test (CNT: $n=7$, FLX14: $n=8, U=8, p=$ 0.0205). (B) FLX22 increased immobile time in forced swim test (CNT: $n=16$, FLX22: $n=18, z=3.088, p=0.0009$ ) and decreased immobile time in tail suspension test (CNT: $n=7$, FLX22: $n=8, U=$ $8, p=0.0205)$. Immobile time is indicated as percent time spent immobile relative to the total time monitored.

8C). However, effects of FLX22 in the forced swim and tail suspension tests were similar to those in $5-\mathrm{HT}_{4}+/+$ and normal C57BL/6J mice (Figure 8D), excluding the possibility that the $5-\mathrm{HT}_{4}$ deficiency nonspecifically suppressed fluoxetine actions. These results further support the idea that the granule cell dematuration is associated with destabilization of home cage activity and increased anxiety-related behaviors, but not with the depressionrelated behaviors.

\section{Discussion}

The present study demonstrated that chronic fluoxetine treatments induced a marked day-to-day fluctuation of activity levels of mice in familiar environments. This novel behavioral effect of fluoxetine was strongly associated with the dematuration of dentate granule cells induced by fluoxetine [9]: 1) Both effects were observed at $22 \mathrm{mg} / \mathrm{kg} /$ day, but not at $14 \mathrm{mg} / \mathrm{kg} /$ day, 2) both effects started emerging in about 2 weeks of the treatment [9], 3) both effects were suppressed in $5-\mathrm{HT}_{4}$ receptor-deficient mice, and 4) the fluctuation of activity levels was negatively correlated with the magnitude of frequency facilitation at the mossy fiber-CA3 synapse, the physiological index of the state of granule cell maturation [9-11,13]. In mice heterozygous for alpha- 


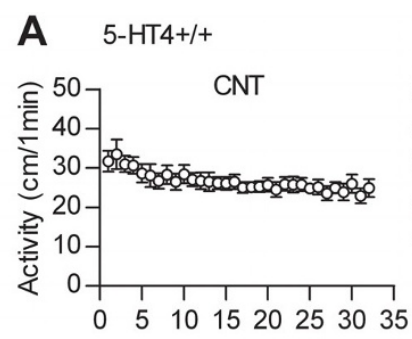

Day

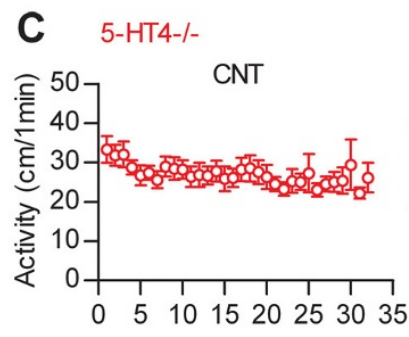

Day

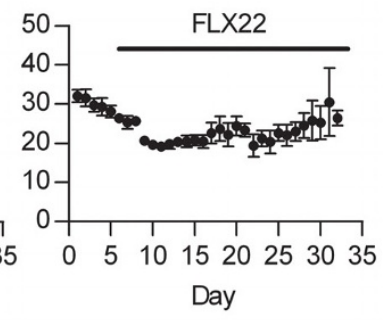

B

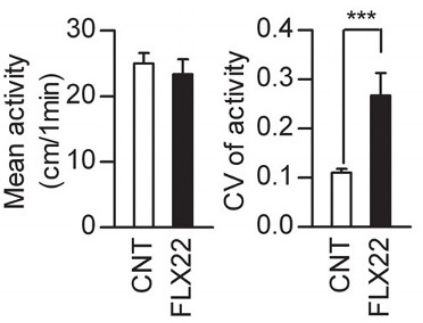

D $\quad 5$-HT4--

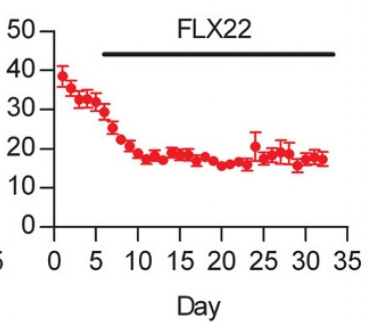

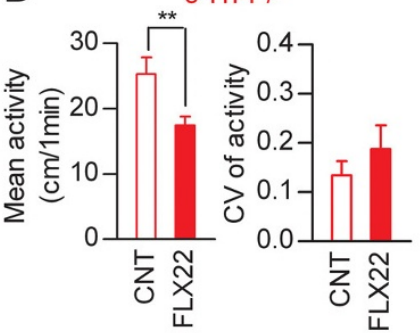

Figure 6 Suppression of fluoxetine-induced behavioral destabilization in $\mathbf{5}-\mathbf{H T}_{\mathbf{4}}$-deficient mice. (A) Averaged data showing home cage activity levels of control and FLX22-treated $5-\mathrm{HT}_{4}+/+$ mice $(n=9$ each). (B) FLX22 increased CV of activity levels during last 2 weeks of treatments in $5-\mathrm{HT}_{4}+/+$ mice $(U=5, p=0.0008)$, but had no significant effect on mean activity levels during the same period $(U=30, p=$ 0.3865). (C) Averaged data showing home cage activity levels of control and FLX22-treated $5-H_{4}-/$ mice ( $n=11$ each). (D) FLX22 reduced mean activity levels during last 2 weeks of treatments $(z=2.627, p=0.0087)$, but had no significant effect on CV of activity in $5-H T_{4}^{-/-}$mice $(z=0.591$, $p=0.5546)$

calcium/calmodulin-dependent protein kinase II (alphaCaMKII+/- mice), the dentate granule cells stay in the immature state even in adults, and these mice also show strongly reduced frequency facilitation at the mossy fiber synapse and aberrant home cage behaviors with large periodic changes in activity levels [11]. These lines of evidence raise the possibility that the abnormality in the state of granule cell maturation causes instability in activity of mice in familiar environments. Since lesion of the hippocampus consistently causes hyperactivity in home cages [14-16], the hippocampus certainly plays an essential role in regulating activity levels in familiar environments. The dematurated granule cells in the fluoxetine-treated mice and immature granule cells in alpha-CaMKII+/- mice exhibit similar and characteristic changes in their functional properties $[9,11]$. Higher excitability in these granule cells would allow propagation of more cortical excitation into the hippocampus, and the reduced mossy fiber synaptic facilitation would impair the instructive role of the mossy fiber input in the induction of associative synaptic plasticity in the CA3 region $[17,18]$. In addition, activity-dependent expression of the immediate early gene c-fos is nearly completely suppressed in both dematurated and immature granule cells in these mice $[9,11]$. These diverse changes in granule cell functioning would substantially modify activity of the hippocampal neuronal circuit [13], thereby quite likely affecting hippocampus-dependent behaviors such as locomotor activity in home cages. It should be noted that immaturity or dematuration of the dentate granule cells can be assessed not only by the electrophysiological method, but also by a real-time PCR or histochemical analysis of expression of molecular markers such as calbindin and tryptophan 2,3-dioxygenase [9,11,19-21]. These molecular markers would be useful in examining a possible association between abnormality in the state of granule cell maturation and behavioral phenotypes in other mutant or drug-treated mice. The aberrant behavioral effect of fluoxetine observed here might be related to adverse effects of fluoxetine and other SSRIs in humans. SSRIs can induce switching to mania or mood destabilization, especially in patients with bipolar disorder [1,5], and the switching to mania can be observed even after discontinuation of SSRI medication [4]. Since the destabilization of mouse behaviors were observed at the dose higher than the clinical therapeutic dose of fluoxetine and suggested optimal dose for mice [22], this effect may not be directly relevant to clinical symptoms or behavioral changes in humans. Although further studies are necessary to clarify the clinical relevance of the present result, our finding indicates that the SSRI fluoxetine has the 


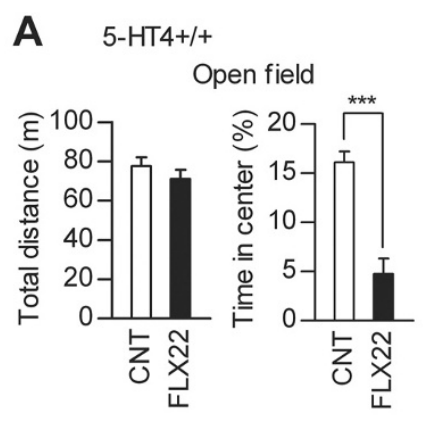

B $5-\mathrm{HT} 4+/+$
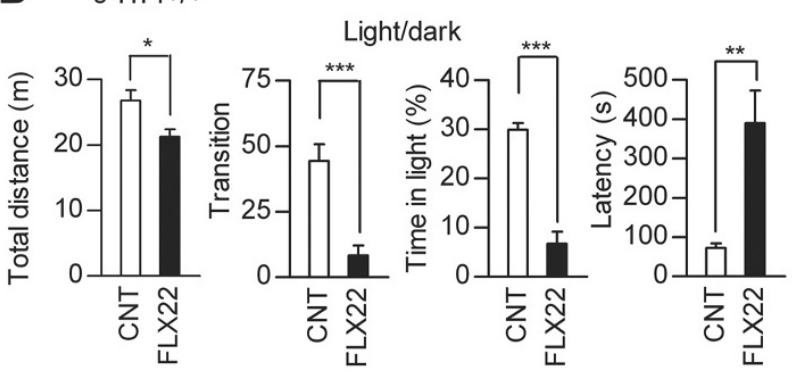

C $5-\mathrm{HT} 4+/+$
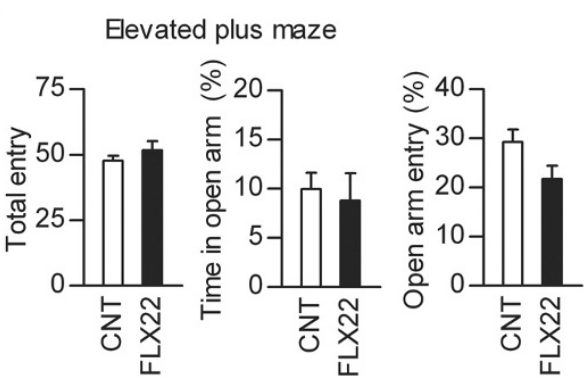

D 5-HT4+/+

Forced swim Tail suspension

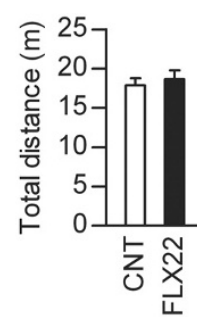

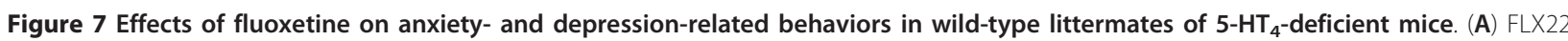
reduced time spent in the center of the open field $(U=3, p=0.0003)$, but had no significant effect on the total distance traveled $(U=28, p=$ 0.3154 ) in 5- $\mathrm{HT}_{4}+/+$ mice (CNT: $\left.n=10, \mathrm{FLX} 22: n=8\right)$. (B) FLX22 reduced the total distance traveled $(\mathrm{U}=15, p=0.0464)$, the number of transition $(U=2.5, p=0.0003)$, and time spent in the light compartment $(U=0, p<0.0001)$ and increased the latency to enter the light compartment $(\mathrm{U}=6, p=0.0025)$ in the light/dark transition test in 5-HT + /+ mice (CNT: $n=9$, FLX22: $n=8)$. Four fluoxetine-treated mice did not enter the light compartment. (C) FLX22 had no significant effects on the total distance traveled $(U=36, p=0.7618)$, the total number of entries into arms $(U=31, p=0.4598)$, time spent on open arms $(z=0.8, p=0.4082)$, or entry into open arms $(U=20, p=0.0831)$ in elevated plus-maze test in 5- $\mathrm{HT}_{4}+/+$ mice (CNT: $n=10$, FLX22: $\left.n=8\right)$. (D) FLX22 increased immobile time in forced swim test in 5-HT4+/+ mice (CNT: $n=$ 10, FLX22: $n=8, U=11, p=0.0085)$, but had no significant effect in the tail suspension test $(U=19, p=0.0676)$. Percent values are calculated as in Figure 3 and 5 .

potential to induce rapid changes in the behavioral state during chronic treatments and after discontinuation of the treatments.

The granule cell dematuration was associated with the increased anxiety-related behaviors in addition to the behavioral destabilization. Some previous studies have also shown that chronic fluoxetine can increase anxietyrelated behaviors $[23,24]$. In our studies using adult mice, the anxiogenic-like effect of fluoxetine was observed at $22 \mathrm{mg} / \mathrm{kg} /$ day, but not at $14 \mathrm{mg} / \mathrm{kg} /$ day or $10 \mathrm{mg} / \mathrm{kg} /$ day [12]. On the other hand, Oh et al. (2009) have shown the anxiogenic-like effect of fluoxetine at as low as $3 \mathrm{mg} / \mathrm{kg} /$ day in juvenile mice [24]. In their study, fluoxetine was administered from the age of 2 through 6 weeks. The magnitude of frequency facilitation at the mossy fiber synapse reaches the mature level at the age of 3 or 4 weeks in mice $[9,10]$. Therefore, at the beginning of such treatment period, many granule cells are supposed to be in the immature state. It is possible that the difference in the state of maturation of granule cells contributes to the higher potency of fluoxetine in increasing anxiety-related behaviors in young mice.
While the present study shows the association between the granule cell dematuration and increased anxietyrelated behaviors, alpha-CaMKII+/- mice, which have immature granule cells, exhibit greatly reduced anxietyrelated behaviors [11]. This apparent discrepancy could be due to differences in neuronal functions in brain regions other than the dentate gyrus. Alternatively, it might be ascribed to differences in physiological properties between the fluoxetine-treated dematurated granule cells and the immature granule cells in alpha-CaMKII $+/$ - mice. The immature granule cells in alpha-CaMKII $+/$ - mice are more easily excited by depolarizing current injection than the fluoxetine-treated dematurated granule cells, but show a faster decline of firing during prolonged depolarization $[9,11]$. Therefore, these two types of granule cells could behave in a quite different way in some occasions, thereby differentially contributing to the same hippocampus-dependent behavior.

Our results demonstrated the involvement of the $5-\mathrm{HT}_{4}$ receptor in some of behavioral effects of fluoxetine. This finding is in line with the previous report showing that subchronic administration of $5-\mathrm{HT}_{4}$ 
A $5-\mathrm{HT} 4-/-$ Open field

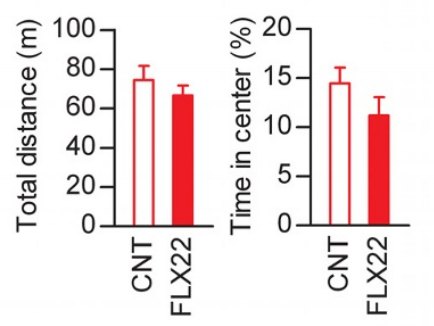

C $5-\mathrm{HT} 4-/-$

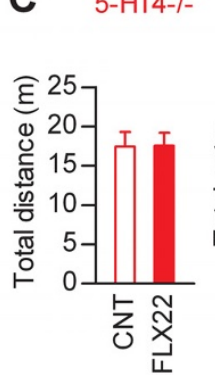

B $5-\mathrm{HT} 4-/-$
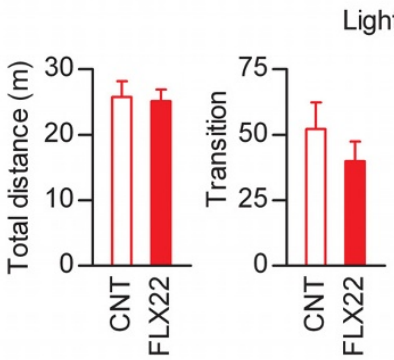

Light/dark

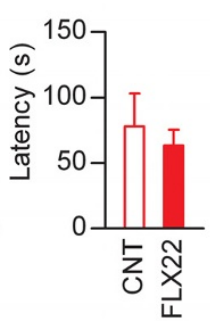

D 5-HT4-/-

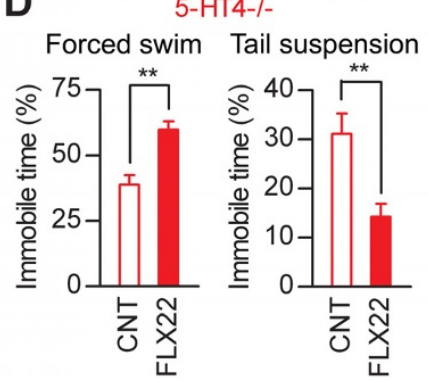

Figure 8 Effects of fluoxetine on anxiety- and depression-related behaviors in $\mathbf{5}-\mathbf{H T}_{\mathbf{4}}$-deficient mice. (A) FLX22 had no significant effects on the total distance traveled $(U=23, p=0.3823)$ or time spent in the center $(U=22, p=0.3282)$ in the open field test in $5-\mathrm{HT}_{4} /$ - mice $(n=$ 8 each). (B) FLX22 had no significant effects on the total distance traveled $(U=30, p=0.8785)$, the number of transition $(z=1.05, p=0.2786)$, time spent in the light compartment $(z=0.735, p=0.4418)$, or the latency to enter the light compartment $(U=31, p=0.9591)$ in the light/dark transition test in $5-\mathrm{HT}_{4}-/$ - mice $(n=8$ each). (C) FLX22 had no significant effects on the total distance traveled $(U=28, p=0.7209)$, the total number of entries into arms $(z=0.945, p=0.3282)$, time spent on open arms $(U=32, p=1)$, or entry into open arms $(U=28, p=0.7209)$ in the elevated plus-maze test in 5- $\mathrm{HT}_{4}-/$ mice $(n=8$ each). (D) FLX22 increased immobile time in the forced swim test $(n=8$ each, $\mathrm{U}=4, p=$ $0.0019)$ and decreased immobile time in the tail suspension test in $5-\mathrm{HT}_{4^{-} / \text {- mice }(~}(n=8$ each, $\mathrm{U}=7, p=0.007)$. Percent values are calculated as in Figure 3 and 5.

receptor partial agonists had antidepressant-like behavioral effects in rats [25]. The $5-\mathrm{HT}_{4}$ receptor is abundantly expressed in the dentate granule cells [26], mediates serotonin-induced synaptic potentiation at the mossy fiber synapse $[9,12]$, and is essential for the granule cell dematuration induced by FLX22 [9]. In $5-\mathrm{HT}_{4} / /$ - mice, FLX22 had no significant effects on fluctuation of home cage activity levels or anxiety-related behaviors. Since we did not observe any obvious difference in behaviors between the $5-\mathrm{HT}_{4}+/+$ and $5-\mathrm{HT}_{4}-/-$ mice of the fluoxetine-free control groups, it is unlikely that behavioral effects of fluoxetine were masked by preexisting behavioral abnormalities in the mutant mice. In addition, FLX22 was still effective in changing some forms of behaviors in $5-\mathrm{HT}_{4}-/$ - mice: FLX22 changed the depression-related behaviors as in $5-\mathrm{HT}_{4}+/+$ and normal C57BL/6J mice and significantly reduced activity levels in the home cages instead of inducing destabilization of activity. Thus, the $5-\mathrm{HT}_{4}$ deficiency does not have nonselective suppressing effects on fluoxetine actions, supporting the specific association between fluoxetine-induced behavioral and cellular changes that are attenuated in the mutant mice. Compan et al. (2004) have reported a significant decrease in open-field locomotor activity in $5-\mathrm{HT}_{4}-/$ - mice [27]. This discrepancy may be due to differences in experimental conditions, most probably the difference in the genetic background of the mutant mice: $129 / \mathrm{Sv}$ in Compan et al. (2004) vs. C57BL/6J in our study.

\section{Conclusions}

Chronic fluoxetine treatments can induce destabilization of home cage behaviors in normal mice that is characterized by occasional switching between hyperactivity and hypoactivity within a few days. This behavioral destabilization was attenuated in mice lacking the serotonin 5$\mathrm{HT}_{4}$ receptor and tightly associated with the fluoxetineinduced dematuration of the dentate granule cells. Based on these results, we propose that the dematuration of dentate granule cells can be a candidate cellular process underlying switching-like changes in the behavioral state that are associated with SSRI treatments. 


\section{Methods}

\section{Drug Treatment}

Male C57BL/6J mice were singly housed from the age of 8 weeks in the institutional standard condition (14:10 light/dark cycle; lights on at 6:00 A.M. through 8:00 P. M.) at $23 \pm 1{ }^{\circ} \mathrm{C}$ with food and water available ad libitum. Following 1 week of acclimation, fluoxetine hydrochloride (Wako Pure Chemical Industries, Ltd., Osaka, Japan) was orally applied at a dose of 14 or $22 \mathrm{mg} / \mathrm{kg} /$ day. In order to minimize stress associated with drug administration, fluoxetine was dissolved in the drinking water. The fluoxetine solutions were prepared everyday, and concentrations of fluoxetine were determined for individual mice based on the water consumption during preceding $24 \mathrm{~h}$ and the body weight measured every other day [9]. Saccharin (0.2\%) was included in the fluoxetine solution to keep water intake comparable to the baseline [9]. Control mice were given water with or without saccharin, and all data were pooled. After 4 weeks of fluoxetine treatments, behavioral tests were started, and fluoxetine treatments were continued during the tests. The $5-\mathrm{HT}_{4}$ receptor heterozygous mutant mice (strain name: B6.129P2-Htr4 < tm1Dgen >/J) were purchased from the Jackson Laboratory (Bar Harbor, ME, USA). These mice had been backcrossed to the C57BL/6J background for 10 generations. Male wildtype $\left(5-\mathrm{HT}_{4}+/+\right)$ and homozygous mutant $\left(5-\mathrm{HT}_{4}-/-\right)$ littermates from heterozygous mating were treated with fluoxetine and used for experiments. There was no significant difference in the actual doses of fluoxetine administered to mice between the genotypes. All procedures were approved by the institutional Animal Care and Use Committee.

\section{Home cage activity monitoring}

Mice were singly housed in the cage $(15 \times 25 \times 30 \mathrm{~cm})$ equipped with an infrared video camera at the top, and locomotor (horizontal) activity in the cage was continuously monitored. Outputs from the cameras were fed into a personal computer. Images were captured at a rate of one frame per second, and the distance traveled per minute was analyzed online using software based on the public domain ImageJ (ImageJ HC8; O'Hara and Co., Ltd., Tokyo, Japan). Since activity of mice during the light period could be affected by external stimuli such as noise made by workers in the animal facility, the activity during the dark period (nocturnal activity) was evaluated in quantitative analyses.

\section{Behavioral experiments}

Mice were transferred to a behavioral testing room and allowed to acclimatize to the environment of the room for at least $1 \mathrm{~h} 30 \mathrm{~min}$ before starting behavioral tests. All tests were performed between 13:30 P.M. and 18:00
P.M. The tests were sequentially performed on different days in the order of the open-field test, light-dark transition test, elevated plus-maze test, forced swim test and tail suspension test. Only one test was conducted for each mouse in a day. Room temperature was kept at 24 $\pm 0.5{ }^{\circ} \mathrm{C}$. To minimize olfactory cues from the previous trial, each apparatus was wiped and cleaned with a hypochlorous acid solution ( 15 ppm, pH 5 - 6.5) before each test except the forced swim test and the tail suspension test.

The open-field test was carried out to examine locomotor activity and anxiety-related behavior in a novel environment. The open-field apparatus composed of opaque white walls and a floor $(50 \times 50 \times 50 \mathrm{~cm})$ was illuminated at an intensity of 40 lux. Each mouse was placed in the center of the open-field arena, and then locomotor (horizontal) activity was monitored for 20 min via a CCD camera positioned above the apparatus. The ambulatory distance and relative time spent in the central zone were measured. To calculate relative time spent in the center, the floor of the apparatus was divided into 25 squares and time spent in the central nine squares was measured. Fluoxetine did not significantly affect vertical activity assessed by measuring the number of infrared photobeam interruption. All records were stored on a PC and analyzed using software based on the public domain ImageJ (ImageJ OF; O'Hara and Co., Ltd., Tokyo, Japan).

The light/dark transition test was carried out to assess anxiety-related behavior. The apparatus for this test was composed of a box $(21 \times 42 \times 25 \mathrm{~cm})$ divided into two compartments of equal size. One compartment was brightly illuminated at an intensity of 600 lux and a CCD camera was equipped on the ceiling, whereas the other was not illuminated (8 lux) and an infrared camera was equipped on the ceiling. The partition dividing the compartments had an opening $(5 \times 3 \mathrm{~cm})$ with a sliding door through which mice could move from one compartment to the other. Single mice were put into the dark compartment and the sliding door was automatically opened after $5 \mathrm{~s}$. The behavior of mice was monitored for $10 \mathrm{~min}$. The total number of transitions between chambers, time spent in each side, the first latency to enter the light side and the distance traveled in each side were recorded automatically and analyzed using software based on the public domain ImageJ (ImageJ LD2, O'Hara \& Co., Ltd., Tokyo, Japan). When mice did not enter the light compartment, the latency was considered $600 \mathrm{~s}$.

The elevated plus-maze test was carried out to examine anxiety-related behavior. The apparatus consisted of a central platform $(5 \times 5 \mathrm{~cm})$, two opposed open arms $(25 \times 5 \mathrm{~cm})$ and two opposed closed arms of the same size, but with $15-\mathrm{cm}$-high opaque walls. The edges of 
the open arms were raised $0.25 \mathrm{~cm}$ to avoid falls of mice. The floor of each arm was made of white plastic. The apparatus was elevated to a height of $50 \mathrm{~cm}$ above the floor and illuminated at an intensity of 40 lux. At the beginning of each test, one of the open arms was blocked by a transparent obstacle and each mouse was placed on the central platform, facing the blocked open arm. After the mouse entered either of the closed arms, the block was removed and the test was started. Activity of mice was monitored for $10 \mathrm{~min}$ via a CCD camera positioned above the apparatus. The time spent in each arm, the number of entries into each arm and the ambulatory distance were recorded and analyzed using software based on the public domain ImageJ (ImageJ EP, O’Hara \& Co., Ltd., Tokyo, Japan).

The forced swim test was carried out to assess depression-related behavior. The apparatus consisted of a transparent plastic cylinder $(22 \mathrm{~cm}$ in height and $12 \mathrm{~cm}$ in diameter $)$ placed in a box $(30.5 \times 40 \times 40 \mathrm{~cm})$. The cylinder was filled with water $\left(25^{\circ} \mathrm{C}\right)$ up to a height of $10 \mathrm{~cm}$ and was illuminated from the bottom of the box. Each mouse was placed into the cylinder and activity was monitored for $15 \mathrm{~min}$ via a CCD camera mounted on the top of the box. Immobile time except for first 2 min was measured. The cylinder was refilled with clean water after each test. All records were stored on a PC and analyzed using software based on the public domain ImageJ (ImageJ PS4, O’Hara \& Co., Ltd., Tokyo, Japan).

The tail suspension test was carried out to examine depression-related behavior. The tip $(1 \mathrm{~cm})$ of mouse tail was securely fastened with adhesive tape to a metallic plate. The plate was hung from the ceiling of a test box $(30.5 \times 40 \times 40 \mathrm{~cm})$. Immobile time was measured for 6 min with a CCD camera mounted on the side of the box. All records were stored on a PC and analyzed using software based on the public domain ImageJ (ImageJ PS4, O’Hara \& Co., Ltd., Tokyo, Japan).

\section{Electrophysiology}

Mice were decapitated under deep halothane anesthesia and both hippocampi were isolated. Transverse hippocampal slices $(380 \mu \mathrm{m})$ were cut using a tissue slicer in ice-cold sucrose-containing saline composed of (in $\mathrm{mM}$ ): sucrose 72, $\mathrm{NaCl} 80, \mathrm{KCl} 2.5, \mathrm{NaH}_{2} \mathrm{PO}_{4}$ 1.0, $\mathrm{NaHCO}_{3}$ 26.2, glucose 20, $\mathrm{CaCl}_{2}$ 0.5, $\mathrm{MgCl}_{2} 7$ (equilibrated with $95 \% \mathrm{O}_{2} / 5 \% \mathrm{CO}_{2}$ ). Slices were then incubated for $30 \mathrm{~min}$ at $30^{\circ} \mathrm{C}$ and maintained in a humidified interface holding chamber at room temperature $\left(24-27^{\circ} \mathrm{C}\right)$ before recordings. Electrophysiological recordings were made in a submersion-type chamber maintained at $27.0-27.5^{\circ} \mathrm{C}$ and superfused at $2 \mathrm{ml} / \mathrm{min}$ with saline composed of (in $\mathrm{mM}$ ): $\mathrm{NaCl} \mathrm{125,} \mathrm{KCl} 2.5$, $\mathrm{NaH}_{2} \mathrm{PO}_{4}$ 1.0, $\mathrm{NaHCO}_{3}$ 26.2, glucose 11, $\mathrm{CaCl}_{2} 2.5$,

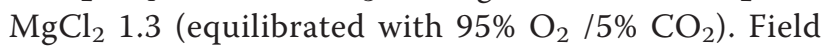

excitatory postsynaptic potentials (fEPSPs) arising from the mossy fiber synapses were evoked by electrical stimulation delivered to the dentate granule cell layer and recorded from the stratum lucidum of CA3 using a glass pipette filled with $2 \mathrm{M} \mathrm{NaCl}$. The amplitude of fEPSPs was measured on analysis as described [28]. A criterion used to identify the mossy fiber input was more than $85 \%$ block of fEPSP amplitude by an agonist of group II metabotropic glutamate receptors, (2 S,2'R,3'R)-2-(2',3'-dicarboxycyclopropyl)glycine (1 $\mu \mathrm{M})$ (Tocris Bioscience, Bristol, UK). Single electrical stimulation was delivered at a frequency of $0.05 \mathrm{~Hz}$ for baseline recordings and frequency facilitation was examined at $1 \mathrm{~Hz}$. All recordings were made using a Multiclamp 700B amplifier (Molecular Devices, Sunnyvale, CA, USA), filtered at $2 \mathrm{kHz}$ and stored in a personal computer via an interface (digitized at $5-10 \mathrm{kHz}$ ).

\section{Statistics}

The number of data $(n)$ represents the number of mice. Since some data from drug-treated mice did not distribute normally, nonparametric tests were used to evaluate statistical significance. The two-tailed MannWhitney test and Dunn's multiple comparison test were used to compare two groups and three groups or more, respectively, with the significance level $P<0.05$. All statistical tests were performed using GraphPad Prism version 3.03 for Windows (GraphPad Software, San Diego, CA, USA).

\section{Acknowledgements}

We thank Yasunori Mikahara and Yoko Oda for technical assistance. This work was supported by the Human Frontier Science Program Organization (to K.K.), Japan Science and Technology Agency, Core Research for Evolutional Science and Technology (to K.K. and H.S.), Grant-in-Aid for Scientific Research from MEXT, Japan (22590249 to H.S. and 22500342 to K. K.), and a grant (S0801035) from MEXT, Japan (to H.S.).

\section{Author details}

'Department of Pharmacology, Nippon Medical School, 1-1-5 Sendagi, Bunkyo-ku, Tokyo 113-8602, Japan. 'Japan Science and Technology Agency, Core Research for Evolutional Science and Technology, Saitama 332-0012, Japan.

\section{Authors' contributions}

KK designed the study, carried out electrophysiological experiments, analyzed the data, and drafted the manuscript. YI carried out behavioral experiments, analyzed the data, and helped to draft the manuscript. HS participated in the design of the study and helped to draft the manuscript. All authors read and approved the final manuscript.

\section{Competing interests}

The authors declare that they have no competing interests.

Received: 14 December 2010 Accepted: 16 March 2011

Published: 16 March 2011

\section{References}

1. Howland $\mathrm{RH}$ : Induction of mania with serotonin reuptake inhibitors. J Clin Psychopharmacol 1996, 16:425-427. 
2. Goodman WK, Murphy TK, Storch EA: Risk of adverse behavioral effects with pediatric use of antidepressants. Psychopharmacology (Berl) 2007, 191:87-96.

3. Stahl SM: Mechanism of action of serotonin selective reuptake inhibitors. Serotonin receptors and pathways mediate therapeutic effects and side effects. J Affect Disord 1998, 51:215-235.

4. Ali S, Milev R: Switch to mania upon discontinuation of antidepressants in patients with mood disorders: a review of the literature. Can J Psychiatry 2003, 48:258-264.

5. Goldberg JF, Truman CJ: Antidepressant-induced mania: an overview of current controversies. Bipolar Disord 2003, 5:407-420.

6. Malberg JE, Eisch AJ, Nestler EJ, Duman RS: Chronic antidepressant treatment increases neurogenesis in adult rat hippocampus. J Neurosci 2000, 20:9104-9110.

7. Santarelli L, Saxe M, Gross C, Surget A, Battaglia F, Dulawa S, Weisstaub N, Lee J, Duman R, Arancio O, Belzung C, Hen R: Requirement of hippocampal neurogenesis for the behavioral effects of antidepressants. Science 2003, 301:805-809.

8. David DJ, Samuels BA, Rainer Q, Wang J-W, Marsteller D, Mendez I, Drew M, Craig DA, Guiard BP, Guilloux J-P, Artymyshyn RP, Gardier AM, Gerald C, Antonijevic IA, Leonardo ED, Hen R: Neurogenesis-dependent and -independent effects of fluoxetine in an animal model of anxiety/ depression. Neuron 2009, 62:479-493.

9. Kobayashi K, Ikeda Y, Sakai A, Yamasaki N, Haneda E, Miyakawa T, Suzuki H: Reversal of hippocampal neuronal maturation by serotonergic antidepressants. Proc Natl Acad Sci USA 2010, 107:8434-8439.

10. Marchal C, Mulle C: Postnatal maturation of mossy fibre excitatory transmission in mouse CA3 pyramidal cells: a potential role for kainate receptors. J Physiol 2004, 561:27-37.

11. Yamasaki N, Maekawa M, Kobayashi K, Kajii Y, Maeda J, Soma M, Takao K, Tanda K, Ohira K, Toyama K, Kanzaki K, Fukunaga K, Sudo Y, Ichinose H, Ikeda M, Iwata N, Ozaki N, Suzuki H, Higuchi M, Suhara T, Yuasa S, Miyakawa T: Alpha-CaMKII deficiency causes immature dentate gyrus, a novel candidate endophenotype of psychiatric disorders. Mol Brain 2008, $1: 6$

12. Kobayashi K, Ikeda Y, Haneda E, Suzuki H: Chronic fluoxetine bidirectionally modulates potentiating effects of serotonin on the hippocampal mossy fiber synaptic transmission. J Neurosci 2008 28:6272-6280.

13. Kobayashi K: Targeting the hippocampal mossy fiber synapse for the treatment of psychiatric disorders. Mol Neurobiol 2009, 39:24-36.

14. Gray JA, MCNaughton N: Comparison between the behavioural effects of septal and hippocampal lesions: a review. Neurosci Biobehav Rev 1983, 7:119-188

15. Cassel J-C Cassel S, Galani R, Kelche C, Will B, Jarrard L: Fimbria-fornix vs selective hippocampal lesions in rats: effects on locomotor activity and spatial learning and memory. Neurobiol Learn Mem 1998, 69:22-45.

16. Coutureau E, Galani R, Jarrard LE, Cassel J-C: Selective lesions of the entorhinal cortex, the hippocampus, or the fimbria-fornix in rats: a comparison of effects on spontaneous and amphetamine-induced locomotion. Exp Brain Res 2000, 131:381-392.

17. Kobayashi K, Poo M-m: Spike train timing-dependent associative modification of hippocampal CA3 recurrent synapses by mossy fibers. Neuron 2004, 41:445-454.

18. Sachidhanandam S, Blanchet C, Jeantet $Y$, Cho YH, Mulle C: Kainate receptors act as conditional amplifiers of spike transmission at hippocampal mossy fiber synapses. J Neurosci 2009, 29:5000-5008.

19. Hagihara H, Toyama K, Yamasaki N, Miyakawa T: Dissection of Hippocampal Dentate Gyrus from Adult Mouse. J Vis Exp 2009, 33: [http:// www.jove.com/details.stp?id=1543].

20. Matsuo N, Yamasaki N, Ohira K, Takao K, Toyama K, Eguchi M, Yamaguchi S, Miyakawa T: Neural activity changes underlying the working memory deficit in alpha-CaMKII heterozygous knockout mice. Front Behav Neurosci 2009, 3:20.

21. Ohira K, Hagihara H, Toyama K, Takao K, Kanai M, Funakoshi H, Nakamura T, Miyakawa T: Expression of tryptophan 2,3-dioxygenase in mature granule cells of the adult mouse dentate gyrus. Mol Brain 2010, 3:26.

22. Dulawa SC, Holick KA, Gundersen B, Hen R: Effects of chronic fluoxetine in animal models of anxiety and depression. Neuropsychopharmacology 2004, 29:1321-1230.
23. Ansorge MS, Morelli E, Gingrich JA: Inhibition of serotonin but not norepinephrine transport during development produces delayed, persistent perturbations of emotional behaviors in mice. J Neurosci 2008, 28:199-207.

24. Oh JE, Zupan B, Gross S, Toth M: Paradoxical anxiogenic response of juvenile mice to fluoxetine. Neuropsychopharmacology 2009, 34:2197-2207.

25. Lucas G, Rymar W, Du J, Mnie-Filali O, Bisgaard C, Manta S, Lambas-Senas L, Wiborg O, Haddjeri N, Piñeyro G, Sadikot AF, Debonnel G: Serotonin(4) (5$\mathrm{HT}(4)$ ) receptor agonists are putative antidepressants with a rapid onset of action. Neuron 2007, 55:712-725.

26. Vilaró MT, Cortés $\mathrm{R}$, Mengod G: Serotonin $5-\mathrm{HT}_{4}$ receptors and their mRNAs in rat and guinea pig brain: Distribution and effects of neurotoxic lesions. J Comp Neurol 2005, 484:418-439.

27. Compan V, Zhou M, Grailhe R, Gazzara RA, Martin R, Gingrich J, Dumuis A, Brunner D, Bockaert J, Hen R: Attenuated response to stress and novelty and hypersensitivity to seizures in $5-\mathrm{HT}_{4}$ receptor knock-out mice. J Neurosci 2004, 24:412-419.

28. Kobayashi K, Suzuki H: Dopamine selectively potentiates hippocampal mossy fibre to CA3 synaptic transmission. Neuropharmacology 2007, 52:552-561.

doi:10.1186/1756-6606-4-12

Cite this article as: Kobayashi et al:: Behavioral destabilization induced by the selective serotonin reuptake inhibitor fluoxetine. Molecular Brain 2011 4:12.

\section{Submit your next manuscript to BioMed Central and take full advantage of:}

- Convenient online submission

- Thorough peer review

- No space constraints or color figure charges

- Immediate publication on acceptance

- Inclusion in PubMed, CAS, Scopus and Google Scholar

- Research which is freely available for redistribution

Submit your manuscript at www.biomedcentral.com/submit
C) Biomed Central 